\title{
Application of LCA by Using Midpoint and Endpoint Interpretations for Urban Solid Waste Management
}

\author{
Sora Yi ${ }^{1,2 *}$, Kiyo H. Kurisu ${ }^{3}$, Keisuke Hanaki ${ }^{1}$ \\ ${ }^{1}$ Department of Urban Engineering, The University of Tokyo, Tokyo, Japan \\ ${ }^{2}$ Daejeon Development Institute, Daejeon, South Korea \\ ${ }^{3}$ Research Center for Advanced Science and Technology, The University of Tokyo, Tokyo, Japan \\ Email: *sora@djdi.re.kr
}

Received 10 July 2014; revised 8 August 2014; accepted 1 September 2014

Copyright (C) 2014 by authors and Scientific Research Publishing Inc.

This work is licensed under the Creative Commons Attribution International License (CC BY).

http://creativecommons.org/licenses/by/4.0/

(c) (i) Open Access

\begin{abstract}
Life cycle assessment (LCA) is one of the most widely used methods of decision support. However, few studies have examined whether stakeholders prefer midpoint or endpoint approaches. In this regard, the present study examines the attitudes toward urban solid waste management, environmental issues, and scenario evaluations by using midpoint and endpoint interpretations of LCA results. This study introduces three types of social groups that typically respond to environmental conflicts: the individualist, hierarchist, and egalitarian groups. Although residents are likely to recognize global impacts as the most important issue, their view is likely to change depending on system and avoided emissions. Consistent with the Seoul Metropolitan Area's new policy designed to increase the incineration ratio, almost half of all respondents preferred the scenario. Noteworthy is that the respondents' preference for midpoint and endpoint decision-making tools is not consistent with that in previous studies. Most of the respondents indicated that the midpoint approach would be better in evaluating environmental systems.
\end{abstract}

\section{Keywords}

LCIA, Environmental Impact, Environmental Damage, Cultural Theory, LIME, Social Preference, NIMBY

\section{Introduction}

Prior to the introduction of a new policy on urban solid waste (USW, solid waste from some municipal fringes is

${ }^{*}$ Corresponding author.

How to cite this paper: Yi, S., Kurisu, K.H. and Hanaki, K. (2014) Application of LCA by Using Midpoint and Endpoint Interpretations for Urban Solid Waste Management. Journal of Environmental Protection, 5, 1091-1103. 
merged with the USW stream) management, the government would usually hold meetings to solicit stakeholders' preferences and perceptions concerning the waste management policy. However, previous research has demonstrated that it is difficult to establish an optimum system based on residents' opinions. Typically, local residents are not aware of the feasibility of various types of solid waste treatment or disposal methods. It is clear that most residents would prefer waste management options with lower costs, easier participation, and reduced environmental burdens [1]. These objectives of USW management systems cannot be achieved simultaneously without a full understanding and consideration of all viewpoints. Therefore, there is a need for effective tools that can help facilitate residents' deeper understanding.

The principal concerns are then the identification of specific factors that motivate NIMBY (not in my backyard) responses and how the present study may elicit a truthful analysis of citizens' preferences for handling important public services of facilities such as USW treatment and disposal facilities, particularly for "backyard" residents.

It is always important to take into account various opinions in any decision making. Because of possible conflicts between individual and general social preferences, the preferences of society as a whole have to be understood from the preferences of a sufficiently large and randomly chosen sample of individuals in a scientifically sound manner [2]. Thus, there have been a number of surveys and statistical evaluations regarding preferences for USW scenarios. As demonstrated by its application to "Eco-indicator 99," grouping people based on cultural theory [3] have been shown to be effective [4] [5]. In risk research, this theory introduces divisions between people according to their dependency on "grids" and "groups" [6]. Here individuals are classified into five groups: the individualist, hierarchist, egalitarian, fatalist, and autonomist groups. As with Eco-indicator 99, the present study considers the individualist, hierarchist, and egalitarian groups.

The individualist group is characterized by weak group incorporation and weak regulation or role prescriptions. Individuals belonging to this group are free to enter into transactions with others as they wish. Boundaries are provisional. The hierarchist group reflects a social environment characterized by strong group boundaries and binding prescriptions. The organizational culture of the Korean central state apparatus has been hierarchical [7] [8]. These prescriptions are justified by the superiority of the whole over the parts (the collective over the individuals). The egalitarian group is characterized by strong group boundaries coupled with few regulations. This group is maintained through intensive relations between group members. Internal role differentiation is minimal.

Life cycle assessment (LCA) is a well-known, practical method of decision support. Decision analysis approaches are beneficial both for planning of an LCA study and for interpreting and understanding the results [9]. However, it is unclear whether the midpoint or endpoint output should be used. The midpoint approach has been widely used, even though it provides a dozen or so impact category indicator results. The endpoint approach has simple and easy-to-understand damage categories, providing results with a lower level of interpretive uncertainty than the midpoint approach [10]. Previous studies [10] [11] have proposed that midpoints can be very useful in the provision of information to stakeholders who do not want uncertain endpoint indicator results in interpretation steps. On the other hand, the endpoint approach is useful for those stakeholders with a low-level of environmental expertise. Social preferences may differ depending on midpoint and endpoint interpretations of LCA applied to determine the environmental performance of USW systems.

For these reasons, the design of this study's questionnaire was based on both interpretations of LCA. It was expected that comparing them would help supplement and extend the decision support tool.

This study defines the attitudes toward USW systems, environmental issues, and social preferences based on midpoint and endpoint interpretations of LCA. The questionnaire survey was designed and applied to Seoul Metropolitan Area (SMA) residents to provide a clearer understanding of the advantages and weak points of each approach.

\section{Materials and Methods}

\subsection{Midpoint and Endpoint Reinterpretations of LCA}

For the survey of social preferences, the illustrative expression was developed based on LCA findings of a study by the authors [12]. The LCA was conducted for USW scenarios developed from the SMA's existing waste flow and management plan [13] by using the LIME (life cycle impact assessment method based on endpoint modeling, 2006 ver.). For both midpoint and endpoint approaches, the LCA results for global-, regional-, and localscale impacts (Table 1) were grouped for additional interpretations. The results of separated nine midpoints 
Table 1. Framework of LCA interpretation at midpoints and endpoints.

\begin{tabular}{|c|c|c|c|c|c|}
\hline \multirow{2}{*}{ Category } & \multirow{2}{*}{ Midpoints } & \multicolumn{4}{|c|}{ Endpoints } \\
\hline & & Human health & Social assets & Biodiversity & Primary plant production \\
\hline \multicolumn{6}{|l|}{ Global impact } \\
\hline Global warming & * & $*$ & * & & \\
\hline Ozone-layer depletion & $*$ & & $*$ & & * \\
\hline Resource consumption & $*$ & & $*$ & $*$ & $*$ \\
\hline \multicolumn{6}{|l|}{ Regional impact } \\
\hline Acidification & $*$ & & $*$ & & $*$ \\
\hline Human toxicity & * & * & & & \\
\hline Eco-toxicity & $*$ & & & $*$ & \\
\hline Eutrophication & $*$ & & $*$ & & \\
\hline \multicolumn{6}{|l|}{ Local impact } \\
\hline Photochemical oxidant & * & & * & & * \\
\hline Waste & & * & & $*$ & $*$ \\
\hline Urban air pollution & * & & & & \\
\hline Land use & & * & & * & $*$ \\
\hline
\end{tabular}

were recalculated as their averages and combined in terms of global, regional, and local impacts. The LCA results for four endpoints were integrated in terms of global, regional, and local impacts.

\subsection{Approach to Social Preferences}

Figure 1 provides a review of the social preference evaluation. Prior to the examination of social preferences, the respondents were classified into three social groups (the individualist, hierarchist, and egalitarian groups) by describing each group to them. The respondents were given five reinterpretation results for them to select one of the four scenarios S1, S2, S3, and S4 (for a review of these scenarios, see Table 2). The two approaches were compared to determine how each group would respond to one combined midpoint interpretation and four endpoint interpretations. First, the data management and frequency/nonparametric analyses of the survey results for all the respondents were conducted using SPSS. Then the cross-tabulation analysis for each group was performed to determine the valuables for their attitudes and preferences. All the p-values were tested for their statistical significance (two-tailed 95\% confidence interval).

\subsection{Questionnaire}

The questionnaire included 31 questions on the respondent's personal background and social attitudes toward USW management, environmental issues, and scenarios. The questionnaire was improved based on the pilot survey, and it was used to survey 1000 SMA residents by using the Internet. The respondents were randomly recruited by Korean Survey Company (World survey: www.wsurvey.net/) and included residents in Seoul City and Gyonggi Province (including 31 administrative cities).

\section{Reinterpretations of LCA Results}

Table 3 shows the reinterpretations of the LCA results for each scenario at one combined midpoint and four endpoints, which were provided to the respondents for the scenario evaluation. Positive values indicate impacts or damage from USW system emissions, whereas negative values indicate impacts or damage from avoided emissions. These results are slightly different from the original interpretation of LCA results [12] because in this study, the classification is limited to 10 levels.

In terms of midpoint results, S4 had the lowest value (i.e., the best performer) for global impacts from USW system emissions (but it performed the worst for regional and local impacts). In terms of net impacts (the USW system impact minus the avoided impact), S2 performed the best at the combined midpoint. S4 performed better than S3 for global impacts, whereas S3 performed better than S4 for regional and local impacts.

In terms of damage to human health, S2, S3, and S4 showed some similarities. S3 was the best performer in terms of net damage, and there was little difference in global damage between S2 and S3 and in local damage 
Table 2. Scenario description.

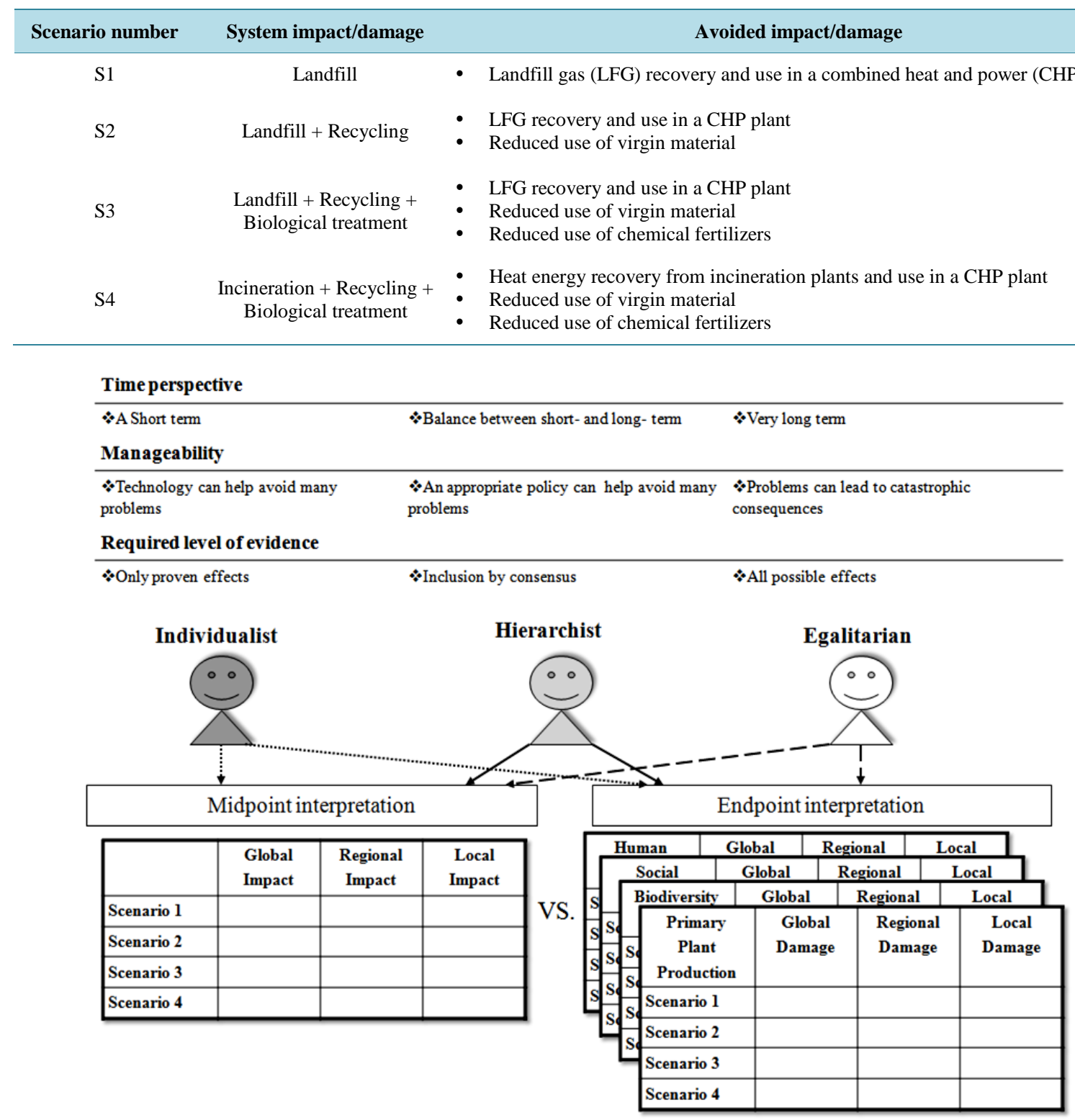

Figure 1. Flow of social preference evaluation.

between S3 and S4. With regard to net damage to social assets, S2, S3, and S4 performed the best. In terms of net damage to biodiversity, S1 and S2 performed the best, and S3 followed closely behind. In terms of net damage to primary plant production, S1, S2, and S3 performed the best.

\section{Results and Discussion}

\subsection{Demographics}

Table 4 shows the socio-demographic characteristics of the respondents. The average age of the respondents was true for that of people in Gyongi Province, not SeoulCity (Sig. 2-tailed: 0.094; the 95 \% confidence interval of the difference: -1.33 - 0.10). Their annual household income, not individual income, was surveyed because their attitudes toward USW management and environmental issues would be influenced by their home environment. 
Table 3. LCA reinterpretations of each scenario.

\begin{tabular}{|c|c|c|c|c|c|c|c|c|}
\hline & \multicolumn{2}{|c|}{ S1 } & \multicolumn{2}{|c|}{ S2 } & \multicolumn{2}{|c|}{ S3 } & \multicolumn{2}{|c|}{ S4 } \\
\hline & $\begin{array}{l}\text { System } \\
\text { emissions }\end{array}$ & $\begin{array}{l}\text { Avoided } \\
\text { emissions }\end{array}$ & $\begin{array}{l}\text { System } \\
\text { emissions }\end{array}$ & $\begin{array}{l}\text { Avoided } \\
\text { emissions }\end{array}$ & $\begin{array}{l}\text { System } \\
\text { emissions }\end{array}$ & $\begin{array}{l}\text { Avoided } \\
\text { emissions }\end{array}$ & $\begin{array}{l}\text { System } \\
\text { emissions }\end{array}$ & $\begin{array}{l}\text { Avoided } \\
\text { emissions }\end{array}$ \\
\hline \multicolumn{9}{|c|}{ Midpoint interpretation } \\
\hline Global impact & 5 & -1 & 7 & -9 & 5 & -9 & 4 & -9 \\
\hline Regional impact & 1 & -1 & 2 & -8 & 5 & -8 & 7 & -8 \\
\hline Local impact & 2 & -5 & 1 & -4 & 2 & -3 & 5 & -1 \\
\hline \multicolumn{9}{|c|}{ Endpoint interpretation } \\
\hline \multicolumn{9}{|c|}{ Human health } \\
\hline Global damage & 2 & 0 & 2 & -1 & 1 & -1 & 1 & -1 \\
\hline Regional damage & 0 & 0 & 1 & -1 & 1 & -1 & 1 & -1 \\
\hline Local damage & 0 & 0 & 4 & -10 & 4 & -10 & 5 & -10 \\
\hline \multicolumn{9}{|c|}{ Social assets } \\
\hline Global damage & 3 & -1 & 9 & -10 & 7 & -10 & 7 & -10 \\
\hline Regional damage & 0 & 0 & 1 & -1 & 3 & -1 & 3 & -1 \\
\hline Local damage & 0 & 0 & 0 & 0 & 0 & 0 & 0 & 0 \\
\hline \multicolumn{9}{|c|}{ Biodiversity } \\
\hline Global damage & 0 & 0 & 1 & -1 & 1 & -1 & 1 & -1 \\
\hline Regional damage & 0 & 0 & 1 & -2 & 1 & -2 & 1 & -2 \\
\hline Local damage & 3 & -10 & 2 & -8 & 1 & -6 & 0 & -1 \\
\hline \multicolumn{9}{|c|}{ Primary plant production } \\
\hline Global damage & 0 & 0 & 6 & -7 & 6 & -7 & 6 & -7 \\
\hline Regional damage & 0 & 0 & 0 & 0 & 0 & 0 & 0 & 0 \\
\hline Local damage & 3 & -10 & 2 & -8 & 1 & -7 & 0 & -2 \\
\hline
\end{tabular}

Table 4. Socio-demographic characteristics of respondents.

\begin{tabular}{|c|c|c|}
\hline Characteristics & Distribution of answers & Notes \\
\hline Sample number & 1000 SMA residents & $\begin{array}{l}\text { The number of SMA residents in 2012: 22,829, } 976 \\
\text { (Seoul City: 10,442,426; Gyeonggi Province: 12,381, 550) }\end{array}$ \\
\hline Gender & Male (511); Female (489) & \\
\hline Age & $\begin{array}{l}10 \text { - } 19(50) ; 20 \text { - } 29(338) ; 30 \text { - } 39 \text { (350); } \\
40 \text { - } 49 \text { (162); } 50 \text { and over }(100)\end{array}$ & $\begin{array}{l}\text { Mean/Standard deviation: 34.4/0.36 (Range14 - 104) } \\
\text { Average age of SMA residents in 2012: } 38.25 \\
\text { (Seoul City: 39.2; Gyeonggi Province: } 37.3)^{*}\end{array}$ \\
\hline Educational level & $\begin{array}{l}\text { High school and below (181); } \\
\text { Undergraduate (647); Graduate (172) }\end{array}$ & \\
\hline Occupation & $\begin{array}{l}\text { Employee (686); Homemaker (99); } \\
\text { Student (154); Other (61) }\end{array}$ & $\begin{array}{l}\text { A total of } 89 \text { respondents had jobs or were students in the } \\
\text { field of environmental or solid waste management. (office, } \\
\text { service or business employees and students: 73; administrative } \\
\text { officers, engineers or researchers: 15; and NGO staff: 1) }\end{array}$ \\
\hline Annual house income ${ }^{* *}$ & $\begin{array}{l}\text { Under } \$ 10,000(109) ; 10,000 \text { - 30,000 (392); } \\
30,000 \text { - 50,000 (326); Over 50,000 (173) }\end{array}$ & $\begin{array}{l}\text { Mean/Standard deviation: } \$ 41,260 / 569.51 \\
\text { Average house income of Metropolitans in 2008: } \$ 43,092^{*}\end{array}$ \\
\hline
\end{tabular}

"Source: Seoul City Statistics in 2012 [14]; Gyeonggi Province Statistics in 2012 [15]. ${ }^{* *}$ USD: recalculated from KRW (the original change rate: 1000 KRW to 1 USD). 


\subsection{Attitudes toward USW Management}

Table 5 shows the questions and answers for attitudes toward USW management. With respect to the existing waste collection system in their city, $19.6 \%$ of the respondents answered "Satisfied," $63.5 \%$, "Somewhat satisfied,” and 16.9\%, "Not satisfied.” The respondents recognized the education program on 3R (reuse, reduction, and recycling) as the most important issue.

Those respondents who saw waste treatment facilities every day, that is, those who lived nearby or passed them on their way to work or school (the "backyard" resident), accounted for $28.4 \%$ of all respondents. Regardless of whether they lived nearby such facilities, a majority (62.7\%) had a negative view of them, and $66.0 \%$ identified risks associated with pollutants and odors from facilities as the reason for such a view.

Compensation in the form of economic incentives has been proposed for "backyard" residents [16]-[18]. With regard to the distance to such facilities, [19] suggested that people located within $300 \mathrm{~m}$ from a facility should be included in "backyard" residents. These residents may be eligible for fringe benefits such as reduced (or ex-

Table 5. Attitudes toward USW management.

Questions

- Answers

Are you satisfied with your city's waste collection system?

- $\quad$ Satisfied

- Somewhat satisfied

- $\quad$ Not satisfied

What do you think is the most important issue to consider in improving the existing USW management?

- Public participation and involvement in waste collection and separation

- Education and involvement in reuse, reduction, and recycling

- Technology development for waste treatment and recycling

- Safety and pollution prevention in waste treatment facilities

Is there a waste treatment facility near you?

- I see a waste treatment facility every day

- I do not see a waste treatment facility every day

Do you have a negative view of waste treatment facilities?

- Very

- Somewhat

- Not at all

What is the main reason why you have a negative view of such facilities?

- A bad view/feeling

- Risks associated with pollution and unpleasant odors from such facilities

- Decreases in the price and value of real estate as a result of such facilities

What do you need if a waste treatment facility were to open near your house?

- A good view

- A clean and odor-free facility

- Compensation for reduced land/housing prices

- Fringe benefits such as reduced heating charges and discounts on welfare facilities
Numbers of responses

Total: 1000

196

635

169

Total: 1000

295

347

276

82

Total: 1000

284

716

Total: 1000

78

549

373

Total: 627

159

414

54

Total: 2000 (Percent)

608 (30\%)

738 (37\%)

$198(10 \%)$

456 (23\%) 
emption from) heating charges and discounts on welfare facilities under Korea's existing compensation policy. Therefore, the survey assessed the respondents' needs based on four options shown in Table 5. Their responses (two options should have been chosen) suggest that people are likely to prefer a good environment (a good view and clean management) to economic compensation.

\subsection{Attitudes toward Environmental Issues}

The questions concerning the most important environmental impact categories were based on global-, regional-, and local-scale impacts, with details shown in Table 1. As shown in Table 6, over half the respondents recognized global impacts as the most important issue. The recognition of each scaled impact varied when various impacts were divided into system (mostly on-site emissions) and avoided impacts (mostly off-site emissions). In the case of system impacts, almost half considered regional impacts to be important. In the case of avoided impacts, 441 respondents recognized global impacts to be the most important issue. According to the Wilcoxon signed-rank test (a nonparametric test), approximately half chose different scaled impacts between the two pairs of questions (between environmental and system impacts and between environmental and avoided impacts), suggesting significant differences in the important scaled impact categories between environmental and system impacts (443 respondents, Asymp. Sig., 2-tailed: 0.000) and between environmental and avoided impacts (522, 0.000). 663 respondents chose different scaled impacts between system and avoided impacts, and the rest kept their opinions.

In terms of the most serious environmental damage categories, most of the respondents chose damage to human health, social assets, and primary plant production, whereas a small number chose damage to biodiversity. The relative importance of the four endpoint categories in this study is different from that in the LIME study reflecting Japanese culture: LIME weighting factors for human health, social assets, biodiversity, and primary plant production were $0.31,0.17$, and 0.25 , and 0.27 , respectively [20].

\subsection{Attitudes toward Scenario}

Before the scenario evaluation based on the LCA results, the respondents' first preference for the scenarios (scenario descriptions in Table 2) was determined. At this point, the respondents were provided with no detailed information on the LCA. The five reinterpreted LCA results (shown in Table 3) were provided, and their preferences were again requested.

\begin{tabular}{|c|c|c|}
\hline \multicolumn{2}{|c|}{ Category } & \multirow{2}{*}{$\begin{array}{c}\text { Distribution } \\
517\end{array}$} \\
\hline \multirow{3}{*}{ Environmental impact } & Global & \\
\hline & Regional & 338 \\
\hline & Local & 145 \\
\hline \multirow{3}{*}{ System impact } & Global & 395 \\
\hline & Regional & 475 \\
\hline & Local & 130 \\
\hline \multirow{3}{*}{ Avoided impact } & Global & 441 \\
\hline & Regional & 352 \\
\hline & Local & 207 \\
\hline \multirow{4}{*}{ Environmental damage } & Human health & 288 \\
\hline & Social assets & 310 \\
\hline & Biodiversity & 134 \\
\hline & Primary plant production & 268 \\
\hline
\end{tabular}


Almost half the respondents selected S4as their primary preference ("Scenario" in Figure 2), and 345 respondents selected S3, the scenario similar to the SMA's existing USW system. However, when the midpoint results were shown, fewer respondents selected S4, and more chose S2 and S3 ("Midpoint” in Figure 2). This may be because of higher regional and local impacts of midpoints estimated in S4.

In the case of human health ("Human"), the majority of the respondents chose S3, because S3 was interpreted as performing the best in terms of net damage, even though there was little difference in global damage between S2 and S3 and in local damage between S3 and S4. In the case of social assets ("Social”), S3 and S4 were equally likely to be selected because of the same reinterpretation results. No global or regional damage and higher local benefits of S1for biodiversity ("Bio") and primary plant production ("Plant") might have increased the respondents' preference for S1. However, the respondents retained their preference for S3 and S4 in the scenario evaluation for biodiversity and primary plant production.

According to the Wilcoxon signed-rank test, there were many changes in scenario evaluations from the respondents' first choice to other choices: biodiversity evaluation (491 respondents, Asymp. Sig. 2-tailed: 0.000), followed by primary plant production $(485,0.000)$, social assets $(402,0.000)$, human health $(399,0.000)$, and the midpoint $(332,0.000)$.

After five scenario evaluations, the respondents were asked to indicate the reasons for selecting each scenario. Six reasons (global, regional, and local impacts; system and avoided impacts; and scenario descriptions) were provided, and they were told to choose up to three (Figure 3). A large number of responses (596 of 2454 responses) indicated that global impacts were the most important reason for the midpoint evaluation. A similar number (520) identified avoided impacts. The respondents considered the local and system impacts on the human health evaluation to be more important than on the midpoint evaluation. There were significant differences in theimportant reasons between the midpoint evaluation and human health, biodiversity, and primary plant production evaluations. A possible explanation for this might be that the participations were responding their environmental values on the six aspects.

Of all the responses (12,184 responses, 100\%), 2732 (22.4\%) were for global impacts, 2372 (19.5\%) were for avoided impacts, 2188(18.0\%) were for system impacts, 2159 (17.7\%) were for regional impacts, 2044 (16.8\%) were for local impacts, and 689 (5.7\%) were for scenario descriptions.

\subsection{Preferences According to Social Groups}

As shown in Table 7, the respondents who identified with the hierarchist group (Group B) accounted for 69.1\% of all respondents, which is consistent with the findings of previous research on Korea's organizational culture.

There was no significant difference among the groups in their gender (Asymp. Sig. 2-tailed: 0.983); age (0.054); education level (0.763); occupation (0.121); and annual house income (0.424) (see Table 4 for all the

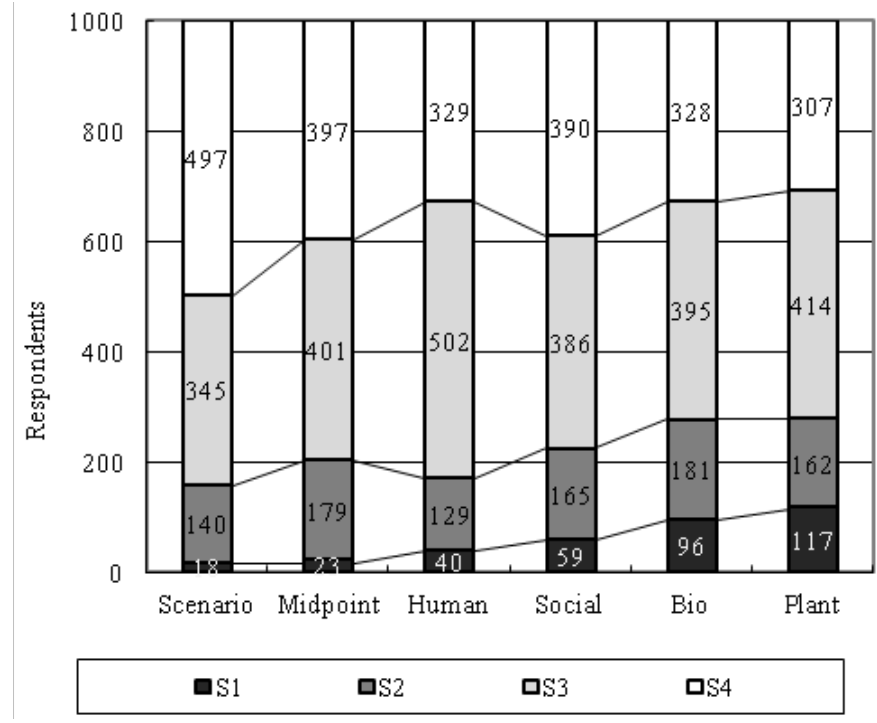

Figure 2. Preference for each scenario. 
Table 7. Distribution of groups based on cultural theory.

Groups Question: What would you do if a USW facility were to be constructed in your area?

Group A: The individualist group I would move to another area after receiving economic compensation.

I would make suggestions for solving regional issues instead of being strongly opposed to the facility.

Group B: The hierarchist group

Group C: The egalitarian group
Respondents

(Total: 1000)

135

691

174

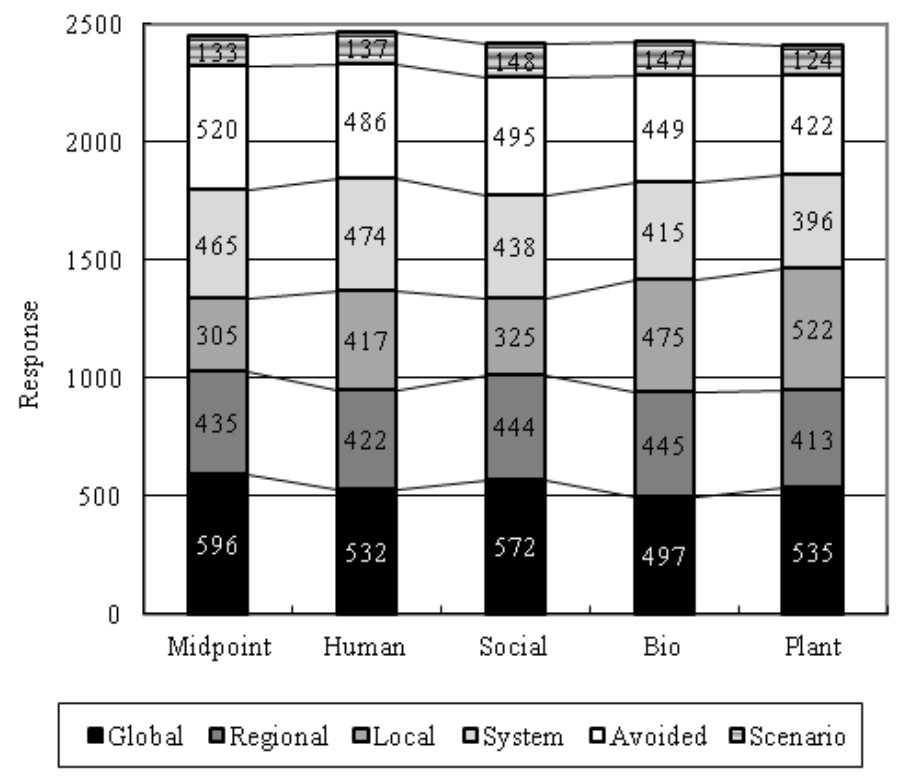

Figure 3. Important aspects in scenario evaluation.

characteristics). However, Group A had a greater proportion of students (20.7\%) than Group B (15.5\%) or Group C (10.9\%); the proportions of employees and homemakers were very similar across the groups. In terms of lowincome households (less than \$10,000), Group A (14.1\%) had a greater proportion of such households than Group B (11.4\%) or Group C (6.3\%).

According to the chi-square test, there were significant differences among the groups in their attitudes toward USW management (see Table 5 for all the characteristics): satisfaction with the waste collection system (Asymp. Sig. 2-tailed: 0.001); important issues to consider in improving USW management (0.001); "backyard” residents (0.024); a negative view (0.012); and the reason behind the negative view (0.001). In terms of important issues to consider in improving USW management, $43.0 \%$ of Group A selected "Public participation and involvement in waste collection and separation," and 33.9\% of Group C selected "Technology development for waste treatment and recycling." Further, 37.5\% of Group B selected "Education and involvement in reuse, reduction, and recycling," with a majority of all respondents supporting this opinion. Group A was more sensitive to "Bad views and feelings toward USW facilities" and "Decreases in the price and value of real estate as a result of USW facilities" than the other groups.

None of the differences in the level of interest in environmental issues among the groups were statistically significant (Asymp. Sig. 2-tailed: 0.074). However, the important impact (0.020) and damage (0.001) categories showed significant differences. Group C (60.3\% of the group) was more sensitive to global impacts than the other groups (see Table 6 for all the characteristics). There were significant differences between the groups in terms of their choice of scaled impacts resulting from system emissions (0.000), whereas there was no significant difference for avoided emissions (0.526). In terms of system impacts, Groups A (52.6\% of the group) and C (46.6\% of the group) were more sensitive to global impacts of than Group B (35.2 \%). Group A (40.0\% of the group) was more sensitive to human health damage than the other groups. 
Figure 4, Figure 5, and Figure 6 show the social preference for each scenario for Groups A, B, and C, respectively. The scenario preferences for scenario descriptions ("Scenario") and five reinterpretations ("Midpoint," "Human," "Social," "Bio," and "Plant") were shown in two different ways. The cobweb charts show the number of respondents who selected each scenario, whereas the bar charts show the total numbers for comparison purposes. According to the cross-tabulation analysis, the three groups differed in terms of their preference for the scenarios (Asymp. Sig. 2-tailed, "Scenario": 0.021; "Midpoint”: 0.014; "Human”: 0.028; "Social”: 0.011; "Bio": 0.011; and "Plant": 0.007). Groups A and C tended to prefer S4, whereas Group B, S3.

Figure 7 and Figure 8 show the results for the reason why each group selected the preferred scenario in terms of the midpoint and human health. All the groups chose global impacts as the most important reason for both the midpoint and human health evaluations. In terms of the midpoint evaluation, all the groups chose the global impact (“Global," Group A: 26.6\%; Group B: 23.2\%; and Group C: 28.3\%), which was followed by the avoided impact (Group A: 18.8\%; Group B: 21.4\%; and Group C: 21.9\%). The results for the human health evaluation are consistent with those for the midpoint evaluation, but there was little difference in the distribution of the six reasons. The respondents belonging to Group B, which accounted for a majority of the respondents, were less likely to change their choices and tended to observe neutrality for environmental conflicts. Group C was more likely to value global impacts and less likely to value scenario descriptions when choosing a scenario than the other groups.
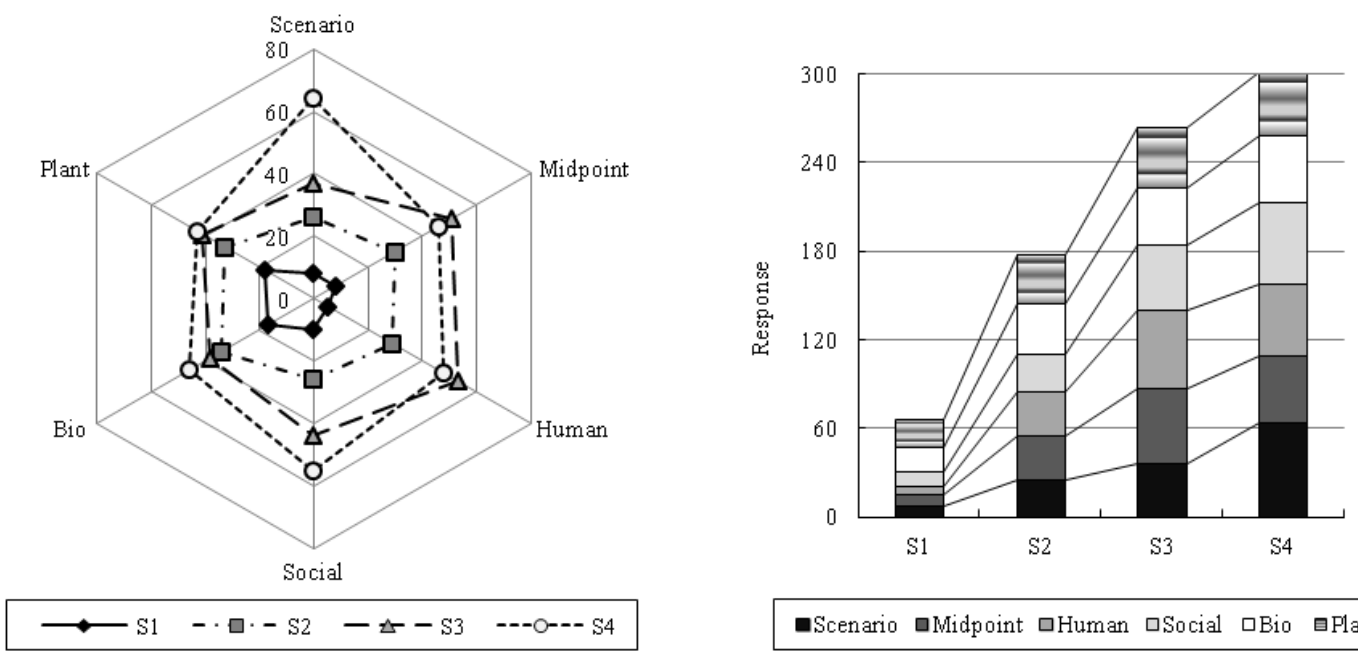

Figure 4. Preferred scenarios: Group A.
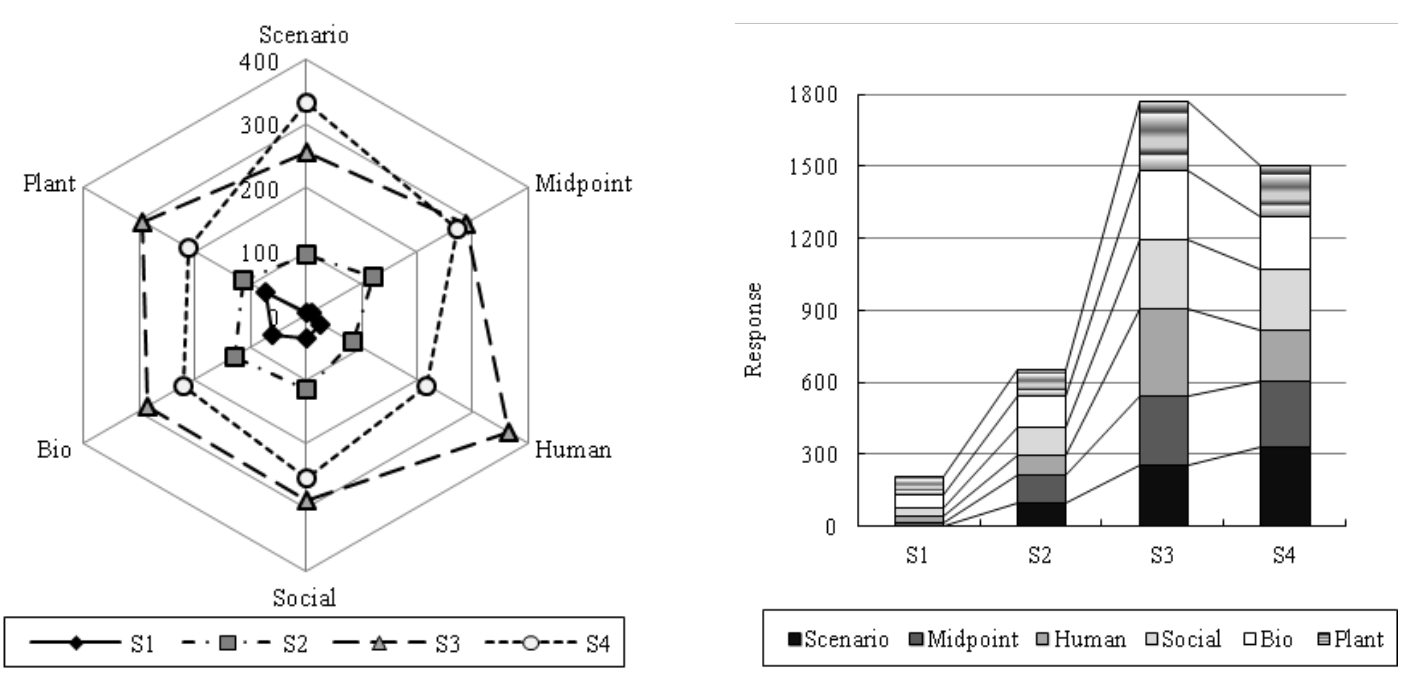

Figure 5. Preferred scenarios: Group B. 

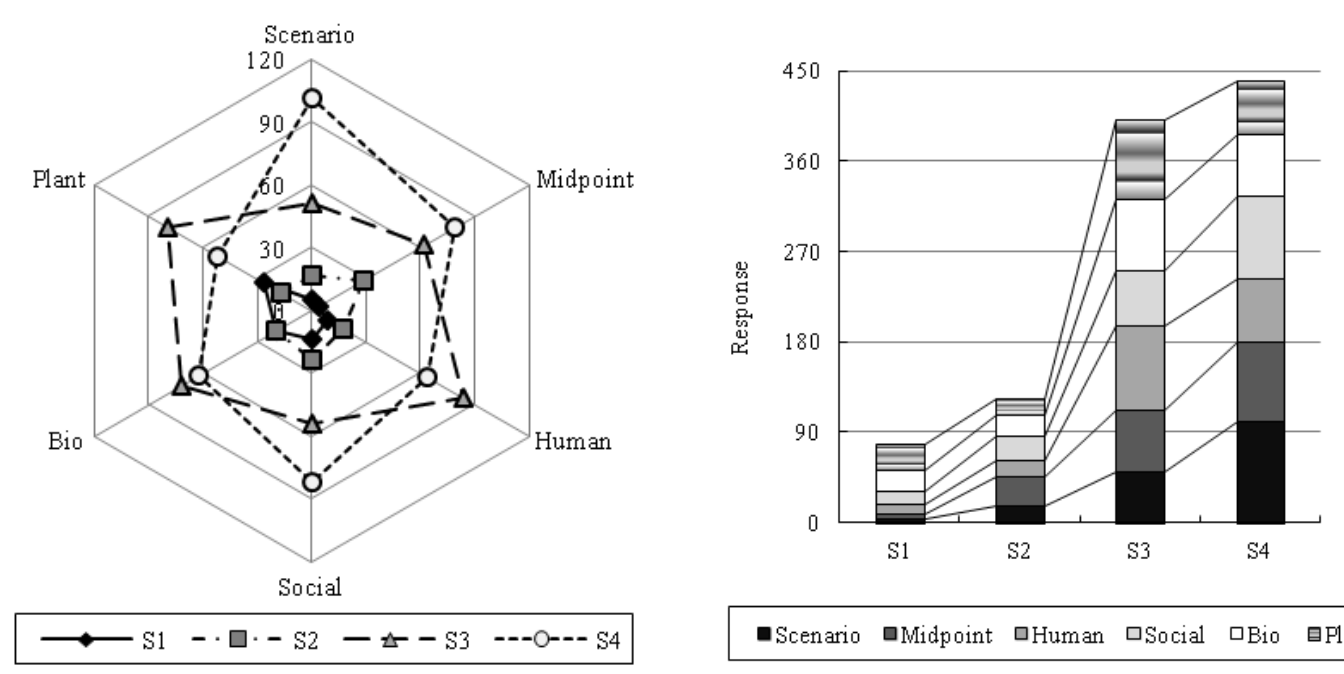

Figure 6. Preferred scenarios: Group C.

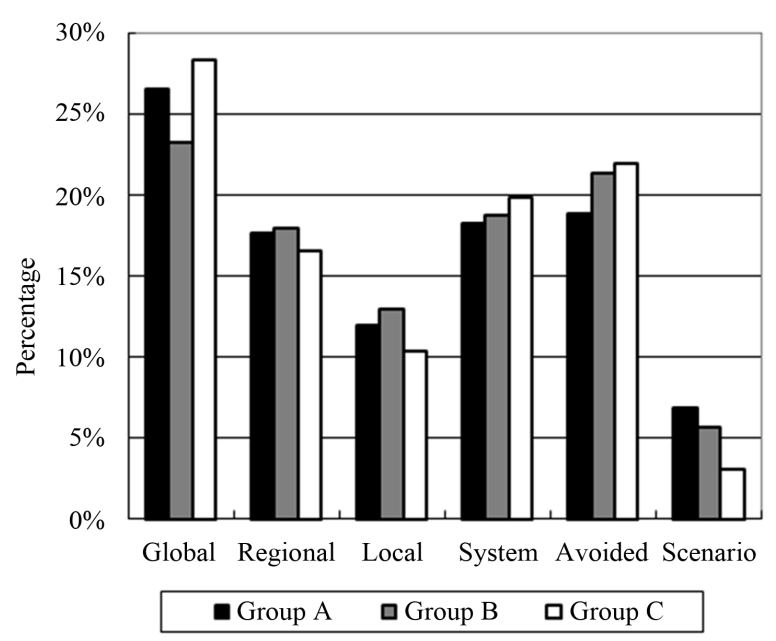

Figure 7. Importance aspectsin midpoint evaluation.

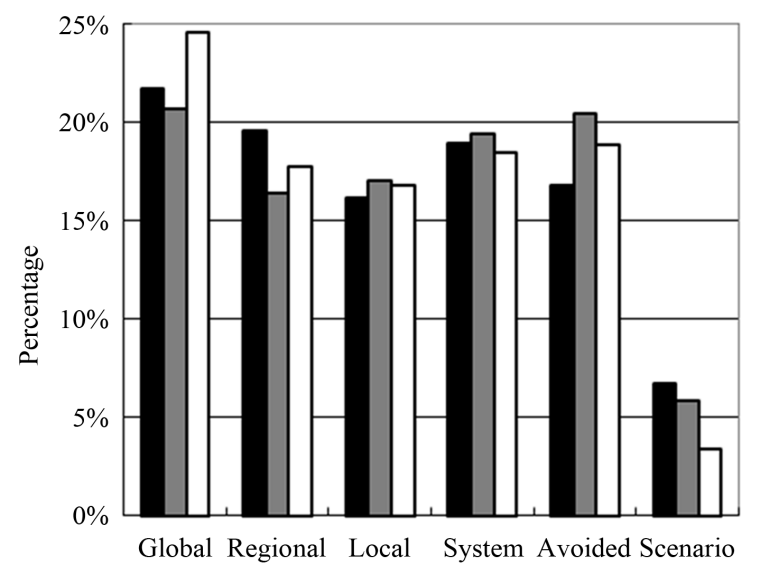

- Group A $\quad$ a Group B $\quad$ 口 Group C

Figure 8. Importance aspects in health damage evaluation. 


\subsection{A Comparison between Midpoint and Endpoint Decision-Making Tools}

The final question addressed the preferred interpretation of LCA between midpoint and endpoint approaches to decision making. The respondents were asked to identify the approach that they preferred. Noteworthy is that $68.2 \%$ preferred the midpoint approach for evaluating environmental systems. According to the cross-tabulation analysis, Group A (76.3\% of this group) was more likely to prefer the midpoint approach than the other groups, but none of the differences were statistically significant (Asymp. Sig. 2-tailed: 0.091). In terms of the subjective questions, the respondents provided two types of answers regarding why they preferred the midpoint approach. In the first type, the respondents explained that the midpoint approach consisted of familiar words such as "global warming” and "acid rain." Such words were familiar (and thus easy to understand) because the respondents encountered them through the Internet, television, radio, newspapers, and other publications, among others. In the second type, the respondents noted that it would be better to evaluate environmental impacts (midpoints) first because environmental impacts would lead to environmental damage.

\section{Conclusions}

The results suggest that USW facilities should focus more on clean management than on economic compensation to "backyard" residents to effectively address NIMBY attitudes motivated by risks associated with pollution.

People are likely to recognize global impacts as the most important issue, but their attitudes may change depending on various conditions, particularly the source of emissions. The results indicate that the relative importance of four endpoint categories in this study is different from that in the LIME study reflecting Japanese culture, suggesting that Korean society may value social assets the most, whereas Japanese society, human health.

Attitudes toward the scenario evaluation changed depending on the given information on scenarios between midpoint and endpoint approaches. There were significant differences in scenario evaluations from the respondents' first choice to other choices. Noteworthy is that almost half the respondents chose S4 (incineration over landfill) as their first preference. This suggests that the Seoul government should observe "due process” in approving any future incineration facilities instead of allowing them "under any circumstances.” However, when the respondents were provided with LCA reinterpretations, their preference for S3 increased. Although there was very little difference in reinterpretation results among the scenarios, the respondents strongly preferred those scenarios with less impacts/damage and more benefits.

The respondents indicated their environmental values for the six reasons for selecting each scenario. The results confirm that social preferences for USW scenarios change depending on social values with respect to global, regional, and local impacts as well as system and avoided impacts.

In terms of social groups which are classified based on the cultural theory, there was no significant difference among the groups in their socio-demographic characteristics and level of interest in environmental issues. However, there were significant differences in their attitudes toward USW management, environmental issues, and scenario evaluations.

Noteworthy is that the respondents' preference for midpoint and endpoint decision-making tools is not consistent with that in previous studies. Most of the respondents indicated that the midpoint approach would be better in evaluating environmental systems. By grouping scaled environmental categories from separated midpoints, evaluating each scenario may become easier for various stakeholders.

The midpoint approach is limited in that separated midpoints with different units cannot be integrated for simplified reinterpretations, and the endpoint approach is limited in that it does not provide the public with a clear understanding of the detailed interpretations of LCA results because of unfamiliar categories.

\section{References}

[1] Kim, K.S. (1992) A Study on Just Compensation in Case of Detestable Facilities. The Journal of Soonchunhyang University, 15, 851-870 (in Korean).

[2] Scharnhorst, W., Köhler, A., Rebitzer, G., Hischier, R. and Jolliet, O. (2004) Progress in Modern Life Cycle Assessment: Practice and Research. 14th SETAC Europe Annual Meeting, 19th-22nd April 2004, Prague.

[3] Thompson, M., Ellis, R. and Wildavsky, A. (1990) Cultural Theory. Westview Press, Boulder.

[4] Goedkoop, M. and Spriensma, R.T. (1999) The Eco-Indicator 99: A Damage Oriented Method for Life Cycle Impact 
Assessment Methodology. PRé Consultants, Amersfoort.

[5] Goedkoop, M., Heijungs, R., Huijbregts, M., De Schryver, AM., Struijs, J. and Van Zelm, R. (2008) ReCiPe 2008. A Life Cycle Impact Assessment Method Which Comprises Harmonised Category Indicators at the Midpoint and the Endpoint Level; First Edition Report I. Characterisation. VROM, Den Haag.

[6] Rippl, S. (2002) Cultural Theory and Risk Perception: A Proposal for a Better Measurement. Journal of Risk Research, 5, 147-165. http://dx.doi.org/10.1080/13669870110042598

[7] Oh, S.G. andChae, J.H. (2003) The Analysis of the Cultural Types of Korean Central State Apparatus Based on the Grid-Group Cultural Theory. Korean Society and Public Administration Research, 14, 45-68 (in Korean).

[8] Kim, S.Y. (2005) Saemanguem Project: Cultural Analysis of Environmental Conflicts. The International Review of Public Administration, 39, 43-66 (in Korean).

[9] Miettinen, P. and Hämäläinenr, P.(1997) How to Benefit from Decision Analysis in Environmental Life Cycle Assessment (LCA). European Journal of Operational Research, 102, 279-294. http://dx.doi.org/10.1016/S0377-2217(97)00109-4

[10] Heijungs, R., Goedkoop, M., Struijs, J., Effting, S., Sevenster, M. and Huppes, G. (2003) Towards a Life Cycle Impact Assessment Method Which Comprises Category Indicators at the Midpoint and the Endpoint Level. The Netherlands. http://www.leidenuniv.nl/interfac/cml/ssp/publications/recipe_phase1.pdf

[11] Lenzen, M. (2006) Uncertainty in Impact and Externality Assessments-Implications for Decision-Making. The International Journal of Life Cycle Assessment, 11, 189-199. http://dx.doi.org/10.1065/lca2005.04.201

[12] Yi, S., Kurisu, H.K. and Hanaki, K. (2011) Life Cycle Impact Assessment and Interpretation of Municipal Solid Waste Management Scenarios Based on the Midpoint and Endpoint Approaches. The International Journal of Life Cycle Assessment, 16, 652-668. http://dx.doi.org/10.1007/s11367-011-0297-3

[13] Yi, S., Yoo, K.Y. and Hanaki, K. (2011) Characteristics of MSW and Heat Energy Recovery between Residential and Commercial Areas in Seoul. Waste Management, 31, 595-602. http://dx.doi.org/10.1016/j.wasman.2010.09.008

[14] Seoul City (2014) Seoul City Statistics 2012. http://stat.seoul.go.kr/index.jsp

[15] Gyongki Province (2014) Gyongki Province Statistics in 2012. http://stat.gg.go.kr/

[16] Schlossberg, H. (1993) HCBs Designed to Convert NIMBY to YIMBY-FAPs. Marketing News 27:2.

[17] Kunreuther, H. and Easterling, D. (1996) The Role of Compensation in Siting Hazardous Facilities. Journal of Policy Analysis and Management, 15, 601-622. http://dx.doi.org/10.1002/(SICI)1520-6688(199623)15:4\%3C601::AID-PAM6\%3E3.0.CO;2-L

[18] Richardson, P.J. (1998) A Review of Benefits Offered to Volunteer Communities for Siting Nuclear Waste Facilities. Geosciences for Development and the Environment, United Kingdom.

[19] Park, S. and Lah, T.J. (2006) The Impact of WTE Facility on Housing Value. International Review of Public Administration, 10, 75-83 (in Korean). http://dx.doi.org/10.1080/12294659.2006.10805070

[20] Itsubo, N. and Inaba, A. (2003) A New LCIA Method: LIME Has Been Completed. The International Journal of Life Cycle Assessment, 8, 305. http://dx.doi.org/10.1007/BF02978923 
Scientific Research Publishing (SCIRP) is one of the largest Open Access journal publishers. It is currently publishing more than 200 open access, online, peer-reviewed journals covering a wide range of academic disciplines. SCIRP serves the worldwide academic communities and contributes to the progress and application of science with its publication.

Other selected journals from SCIRP are listed as below. Submit your manuscript to us via either submit@scirp.org or Online Submission Portal.
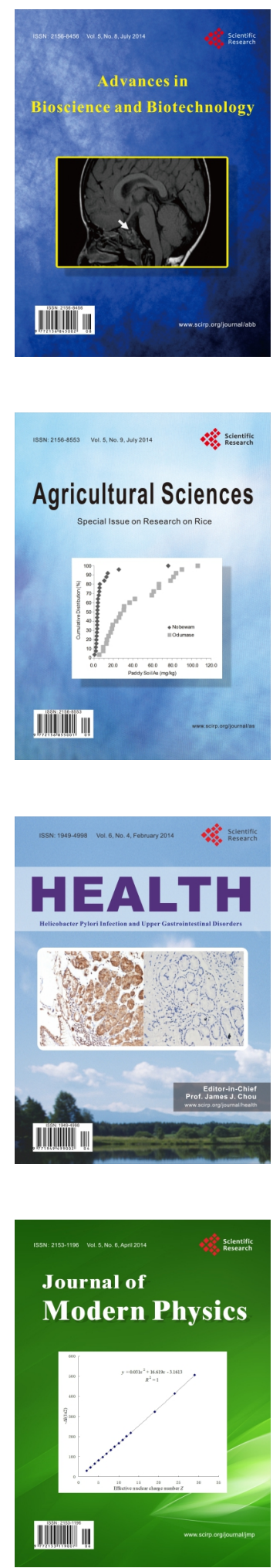
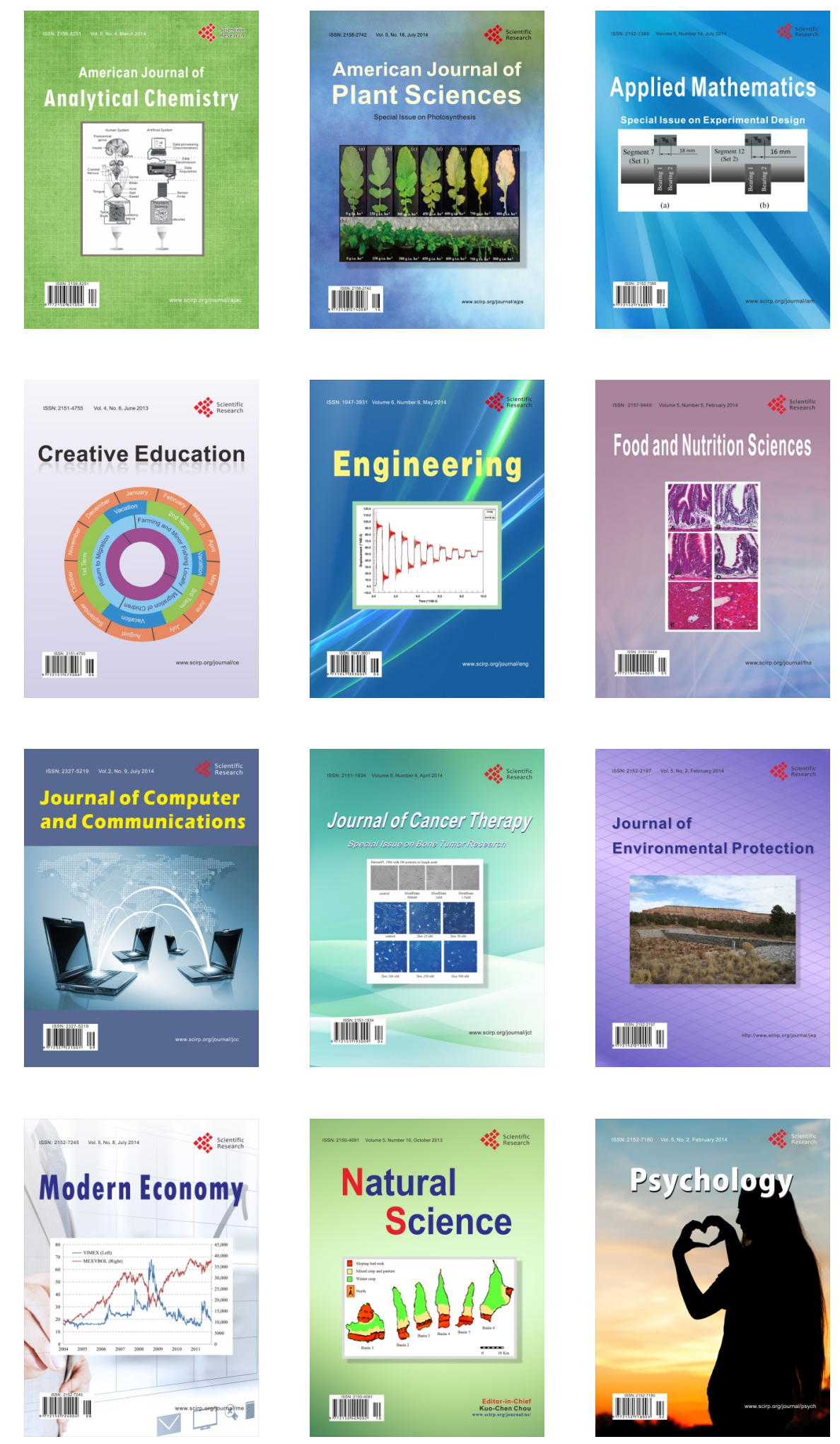